\title{
Ice flow variations at Polar Record Glacier, East Antarctica
}

\author{
QI LIANG, ${ }^{1-3,}$ @ CHUNXIA ZHOU, ${ }^{1,2}$ IAN M. HOWAT, ${ }^{3,4}$ ๑ SEONGSU JEONG, ${ }^{4 *}$ \\ RUIXI LIU, ${ }^{1,2}$ YIMING CHEN ${ }^{1,2}$ () \\ ${ }^{1}$ Chinese Antarctic Center of Surveying and Mapping, Wuhan University, Wuhan, China
${ }^{2}$ Key Laboratory of Polar Surveying and Mapping, National Administration of Surveying, Mapping and Geoinformation, \\ Wuhan University, Wuhan, China \\ ${ }^{3}$ School of Earth Sciences, The Ohio State University, Columbus, Ohio, USA \\ ${ }^{4}$ Byrd Polar and Climate Research Center, The Ohio State University, Columbus, Ohio, USA \\ Correspondence: Chunxia Zhou <zhoucx@whu.edu.cn>
}

\begin{abstract}
Relatively little is known about the physical mechanisms that drive the dynamics of the East Antarctic outlet glaciers. Here we conduct a remote-sensing investigation of the Polar Record Glacier (PRG), East Antarctica to analyze its ice flow acceleration, ice front variations and ice surface melting. Ice flow speeds at PRG increased by up to $15 \%$ from 2005 to 2015, with substantial interannual fluctuations. The ice velocities also showed seasonal variations, accelerating by up to $9 \%$ between September and January. Multiple mechanisms contribute to the observed seasonal variations: the initial acceleration may result from the lost back-stress provided by the sea ice in the austral spring and the later speedup relate to the surface meltwater that leads to weakened ice shelf and shear margins. The sensitivity of the PRG to oceanic forcing is confirmed by comparing the secular ice velocity increases with ocean temperatures. These measurements suggest that the dynamics of East Antarctic ice shelves are sensitive to melt at both the surface and base, at a range of timescales.
\end{abstract}

KEYWORDS: glacier flow, ice velocity, melt-surface

\section{INTRODUCTION}

Changes to a marine-terminating glacier's dynamic state, caused by processes such as iceberg calving, increased ice discharge and ice shelf thinning or thickening, can lead to abrupt changes in mass balance and, thus, contribution to sea level rise. Long-term acceleration may be a response to ice front retreat and increased basal melting of the ice shelf (Paolo and others, 2015). Frontal retreat and thinning would reduce the buttressing that ice shelves provide to the grounded ice upstream (Dupont and Alley, 2005). Once a retreat of ice sheet that sitting on a bedrock that is below sea level (termed the marine-based ice sheet) begins, a feedback between retreat, increased discharge and thinning, termed the Marine Ice Sheet Instability, tends to promote a continued retreat (Weertman, 1974; Schoof, 2007).

It is important to separate the trend in acceleration from seasonal speed variations because the interannual change may be falsely detected due to the artifact of measuring the flow in different seasons. Seasonal glacier velocity variations have been observed in Antarctica and may result from different mechanisms. At the Totten Ice Shelf, the seasonal ice shelf acceleration has been reported recently and is most likely mainly related to the loss of buttressing upon the breakup of rigid sea ice at the ice front (Greene and others, 2018). While the seasonal speed variations at Larsen B glaciers were attributed to the surface meltwater percolation to the bed and a reduction of basal resistance (Scambos and others, 2004). It has also been shown by modeling that the ice mélange forcing against the ice front can prevent crevasse propagation and shut down calving at the terminus (Krug and others, 2015; Robel, 2017). However this mechanism, which

* Present address: University of California Irvine, Irvine, CA, USA. could explain seasonal velocity variations on many outlet glaciers in Greenland (Howat and other, 2010; Cassotto and others, 2015), has not yet been confirmed in Antarctica.

Despite having several times the volume of marine-based ice compared with that of West Antarctica (Fretwell and others, 2013), East Antarctica receives less attention because of its apparent relative stability, with a near-zero or slightly positive mass balance (Shepherd and others, 2012; The IMBIE team, 2018). However, recent observations reveal that nearly half of East Antarctica's ice shelves began to thin after about 2003 (Pritchard and others, 2012; Rignot and others, 2013, 2019; Paolo and others, 2015, 2016), and some East Antarctic ice shelves, particularly the small to medium ice shelves, show negative mass balances as glaciers accelerate and termini retreat (Miles and others, 2013, 2016; Liu and others, 2015).

Polar Record Glacier (PRG, $69.75^{\circ} \mathrm{S}, 75.5^{\circ} \mathrm{E}$ ) is a relatively small outlet glacier located on the east of the Amery Ice Shelf on the southern shore of Prydz Bay. It flows between Meknattane Nunataks and Dodd Island into the central part of the Publications Ice Shelf (Cruwys and Rees, 2001). In 1973, PRG was comprised of a grounded outlet glacier and an ice tongue extending over $42 \mathrm{~km}$ from its grounding line to the ice front. Landsat Thematic Mapper (TM) images acquired in 1989 indicate that the southern section of the ice tongue broke away from the glacier, forming an iceberg $\sim 26 \mathrm{~km}$ long and $16 \mathrm{~km}$ wide. The area of the iceberg progressively decreased through several small break-up events until it completely disintegrated and drifted away in 2015. Meanwhile, the ice flow velocity of PRG varied seasonally during the period 1996-2008 (Zhou and others, 2014). However, unlike the outlet glaciers in West Antarctica or the large glaciers drain the Aurora Subglacial Basin (e.g. Totten Glacier), the physical mechanisms behind this 


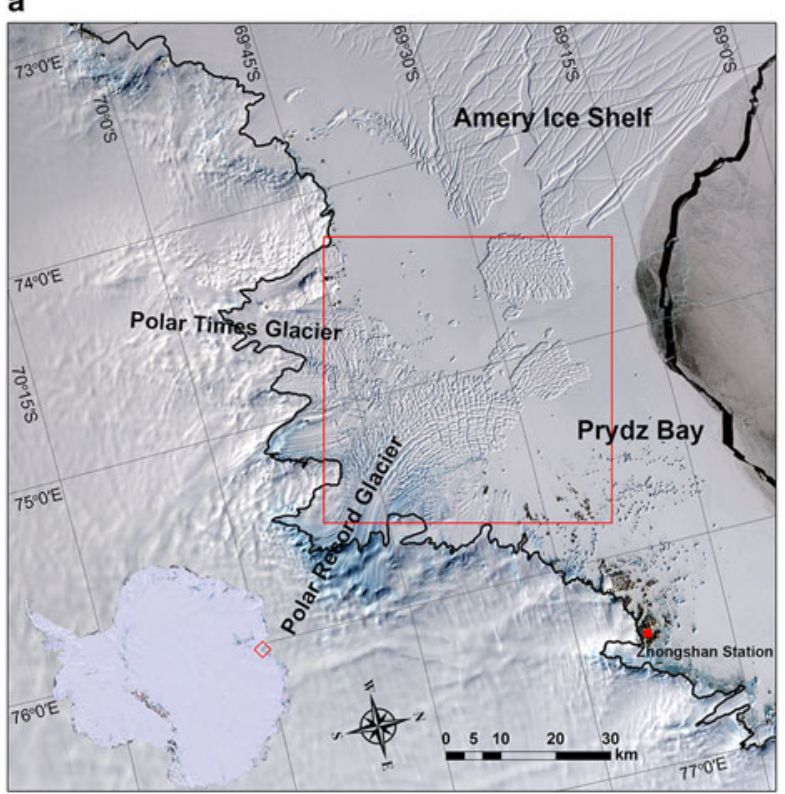

b

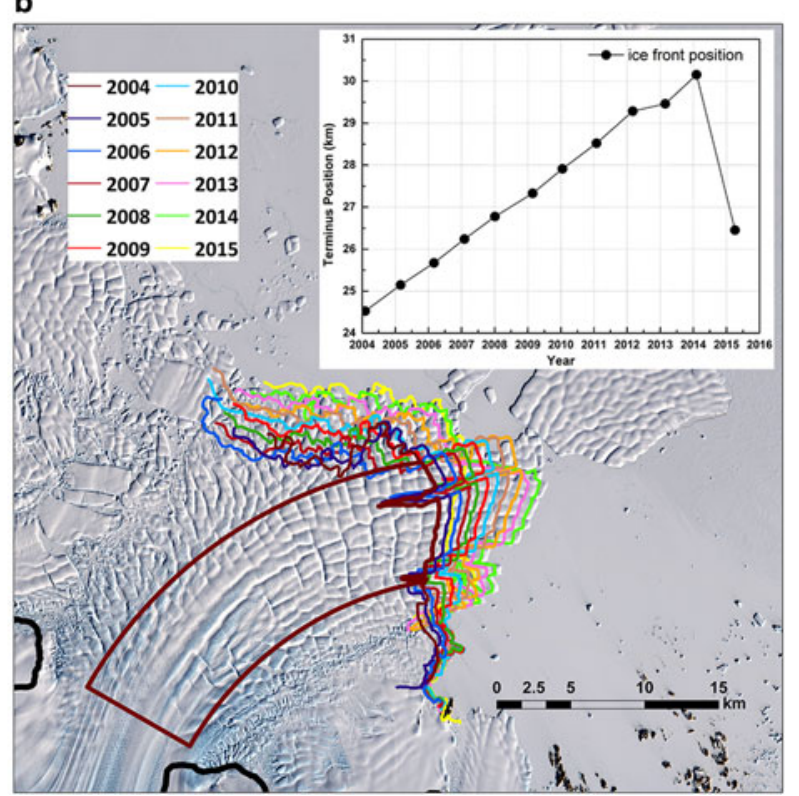

Fig. 1. (a) Landsat-8 image of the PRG acquired on 25 September 2014. The black curve shows the ASAID grounding line (Bindschadler and others, 2011). (b) The variations of the ice front position from 2004 to 2015 . The background is the area in (a) indicated by the red box. The dark red polygon is the curvilinear box used for obtaining an average front position change as described in the text. The initial 2004 polygon is shown as an example. The inset plots the change in ice front position as the mean distance between the ice front and the reference line.

dynamic change and possible climatic and oceanic forcings, remain unclear.

In this paper, we present a remote-sensing investigation of the dynamic changes at the PRG for the period 2005-2015. We measure and analyze spatial and temporal variations in surface melting, flow velocity and ice front position at seasonal and interannual timescales, and compare these with variability in possible environmental forcings including air and ocean temperature and sea ice concentration.

\section{DATA AND METHODS}

\subsection{Ice velocity}

We obtained all available cloud-free panchromatic-band images from the Enhanced Thematic Mapper Plus (ETM+) aboard Landsat 7 and those from the Operational Land Imager (OLI) aboard Landsat 8 acquired from 2004 to 2015 from the United States Geological Survey (USGS). We measured the velocities from repeat imagery spanning 32, 48 and 368 days. Of these, the shorter values provide a balance between having enough displacement and optical coherence of the features. The annual separations (368 days) kept the solar altitudes almost the same for each image pair. We paired only images of the same path/row to reduce terrain-induced errors. Several Sentinel-1 images were acquired from June 2016 to April 2017, and these were used as a supplement to further constrain variations in winter velocity.

Ice surface velocity was mapped from Landsat using the Multi-Image, Multi-Chip (MIMC) Repeat-Image Feature Tracking (RIFT) software (Ahn and Howat, 2011; Jeong and others, 2017), applied to pairs of Landsat images. This method uses multi-directional matching and a priori velocity information to constrain both the search area and postprocessing, improving the quality of the displacement measurements. Errors mainly result from the coregistration and ambiguity of the matches between images. The total displacement errors are typically $1 / 3$ of a pixel. To identify the austral winter ice surface velocity, we performed offset tracking with Sentinel-1 SAR data (Strozzi and others, 2002).

\subsection{Ice front position}

The Landsat images were also used to map the ice front positions. The images acquired during the austral summer were chosen when sufficient coverage was available. We manually traced the coastlines in each image. Each scene was coregistered to the earliest one using stationary control points over exposed rock. From the coregistered images, the glacier terminus changes were tracked using the curvilinear box method (Lea and others, 2014), which is a modification of the rectilinear box method (Moon and Joughin, 2008; Howat and Eddy, 2011). For the rectilinear box method, the ice front is manually traced between two parallel lines approximating the glacier shear margins. With each measurement, a polygon is formed around the traced ice front, with the stationary lateral sides and a stationary bounding line perpendicular to the lateral bounds set at an arbitrary distance up the glacier. Differences in multiple polygons show the change in the area of the ice front, and dividing that change in area by the distance between the lateral bounds gives the average change in distance of the ice front. To better characterize the front position changes for fjords that curve, the curvilinear box method generates a fixed-width box parallel to the glacier's center streamline.

\subsection{Daily air temperatures}

To evaluate the impact of climate forcing on ice velocity, we calculated the daily average air temperatures using the meteorological data from the automatic weather station at Zhongshan Station, $50-\mathrm{km}$ east of PRG. The automatic weather station has recorded hourly air temperatures since 
1989. Furthermore, we calculated the Cumulative Positive Degree Days (CPDD), which is the total sum of daily average temperatures above $0{ }^{\circ} \mathrm{C}$, from the daily air temperature data over the austral summer season.

\subsection{Glacier surface melt}

Using the cloud-free Landsat 7 ETM+, Landsat $8 \mathrm{OLI}$ and ASTER (Advanced Spaceborne Thermal Emission and Reflection Radiometer) images for the period 2005-2015, we measured the areas of meltwater lakes visible in the images. Since the meltwater lakes only formed during austral summer at PRG, only images from December to February were used. To precisely identify water-covered pixels, we first employed a band thresholding method that uses the ratio of blue to red band reflectance values. For each image, the thresholding was determined manually. Meltwater features were then manually checked to eliminate false identifications with multiple band combinations.

\subsection{Ocean model output}

To investigate potential oceanic forcing on the PRG ice shelf, we obtained time series of the monthly ocean temperatures between 2005 and 2015 from the Estimating the Circulation and Climate of the Ocean, Phase II (ECCO2) (Menemenlis and others, 2008) ocean model. We calculated the mean vertical ocean temperatures between 250 and 600 $\mathrm{m}$ depth, which correspond to the depths of the modified Circumpolar Deep Water (mCDW) that has been linked to variability in the ice-shelf basal melt (Herraiz-Borreguero and others, 2015; Williams and others, 2016). To fully cover the range of $\mathrm{mCDW}$ and reduce the uncertainty of the cavity geometry and ocean bathymetry data used by ECCO2, ocean temperatures were averaged over the area shown in Figure $7 \mathrm{a}\left(68.5-69.75^{\circ} \mathrm{S}, 74-78^{\circ} \mathrm{E}\right)$.

\subsection{Sea ice concentration}

We calculated daily sea ice concentrations at the glacier front from the sea ice concentration products derived from the ARTIST sea ice algorithm (Spreen and others, 2008). These products provide complete coverage from 1 Jun 2005 to 31 May 2015 by using AMSR-E, SSMIS and AMSR2 data, with a spatial resolution of $6.25 \mathrm{~km}$. We extracted sea ice concentrations from 91 gridcells at the glacier fronts (shown in Fig. 7a), where the fast ice usually forms (Fraser and others, 2011).

\section{RESULTS}

\subsection{Ice front position changes}

The ice front of the PRG continuously advanced from 2004 to 2012 at a rate equal to the ice flow speed of $\sim 600 \mathrm{~m} \mathrm{a}^{-1}$ (Fig. 1b), in agreement with the findings of Liu and others (2017a). A small calving event in 2012 slightly reduced the total advance for that year. In 2015, a large rift opened in the ice tongue at $\sim 3 \mathrm{~km}$ from the ice front, leading to the calving of an iceberg and a large ice front retreat (Fig. S1).

\subsection{Ice surface velocity from 2005 to 2015}

The map of the average annual ice flow speed (Fig. 2a) shows that speeds increase toward the ice front, reaching $\sim 900 \mathrm{~m}$
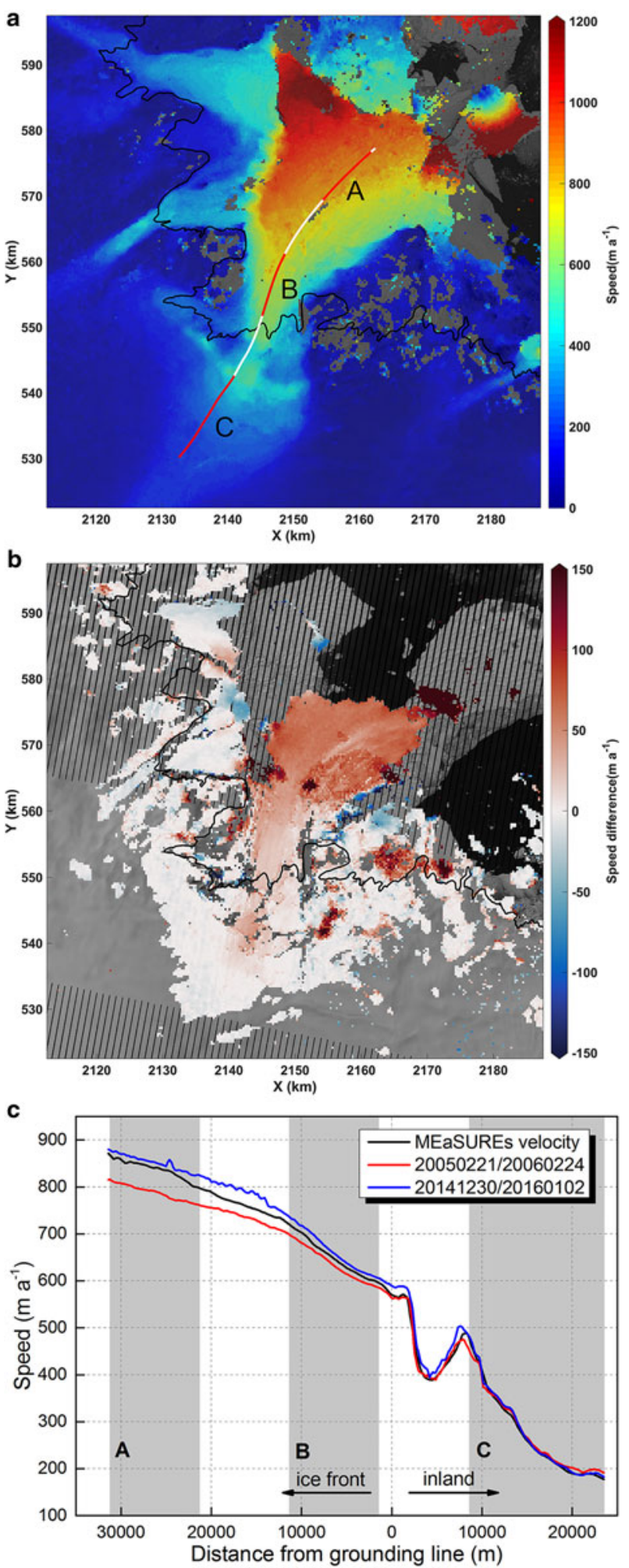

Fig. 2. (a) Ice flow speed map derived from Landsat-8 image pairs from 14 December 2014/31 January 2015. The white line indicates the position of the central flowline. The red lines A, B and $\mathrm{C}$ indicate the sections of the streamline used to calculate the speed shown in Figure 3. (b) Maps of the speed differences between 2005 and 2015. The background is the Landsat-7 image acquired on 24 February 2006. (c) Speed profile along the streamline in (a). The gray shading indicates the position of the three chosen sections.

$\mathrm{a}^{-1}$. Speed differences obtained by using the speed derived from the image pair from 30 December 2014/2 January 2016 minus the result derived from image pair from 21 

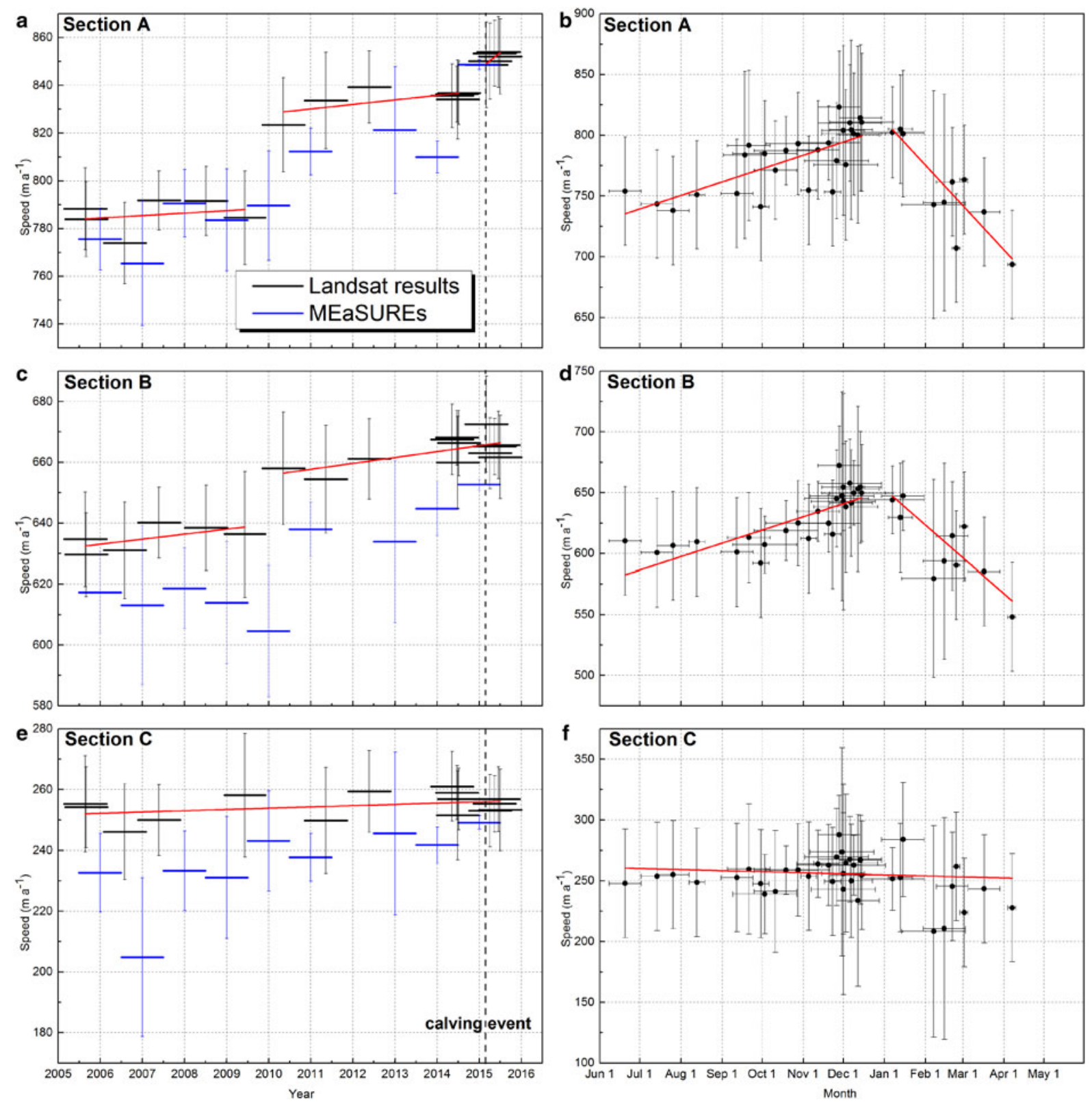

Fig. 3. Interannual (a, c, e) and seasonal (b, d, f) variations in the PRG flow speeds along the three chosen sections over the profile shown in Figure 2c. Velocities in black with vertical error bars are the 1-sigma measurement errors and the horizontal bars are the temporal baselines of the image pairs. The lines that best fit the temporal subsets of the data are shown in red. The blue bars in (a), (c) and (e) are from the MEaSUREs Annual Antarctic Ice Velocity Maps. The vertical dashes denote the timings of large calving events occurring in March 2015. The plots (b), (d) and (f) show measurements from all years by the time of year.

February 2005/24 February 2006 are also shown in Figures $2 \mathrm{~b}$, c, along with observations from the MEaSUREs InSARBased Antarctica Ice Velocity Map (Version 2) (Rignot and others, 2011; Mouginot and others, 2012), which are used for reference. We find that the ice speed increased by up to $\sim 80 \mathrm{~m} \mathrm{a}^{-1}$ at the ice front and by $\sim 30 \mathrm{~m} \mathrm{a}^{-1}$ at the grounding line, with no resolvable change above.

To further examine interannual changes in ice speed, we plot the time series of the averaged speeds of the three chosen sections over the profile shown in Figure 2a, located between 21 and $31 \mathrm{~km}, 1$ and $11 \mathrm{~km}$ and 9 and $24 \mathrm{~km}$ from the grounding line, respectively (Figs 3a, c, e). Compared with the MEaSUREs annual ice velocity (Mouginot and others, 2017), the Landsat estimates are slightly higher. This may be attributed to the different sampling times between our results and the MEaSUREs annual speeds. A secular speed increase over the ice shelf from 2005 (Figs 3a, c) is, however, confirmed by both results. While we clearly resolve acceleration over sections $\mathrm{A}$ and $B$ on the ice shelf, no speed increase over the grounded ice (section C) is resolved. From 2005 to 2010, there was an insignificant increasing trend of $\sim 2 \mathrm{~m} \mathrm{a}^{-1}$ over both sections. In 2010, the speeds abruptly increased by $40 \mathrm{~m} \mathrm{a}^{-1}$ and $20 \mathrm{~m} \mathrm{a}^{-1}$, or by $3-5 \%$, for the sections $A$ and $\mathrm{B}$, respectively. The speeds then increased at a similar rate as before 2010 in both sections, with another abrupt increase of $10 \mathrm{~m} \mathrm{a}^{-1}$ after the 2015 calving event in section A, but not in section B.

To detect seasonal variations in speed, we analyzed all speed measurements from 2005 to 2017, including both those derived from Landsat image pairs with 32 or 48-day baselines or from Sentinel-1 scenes (Figs 3b, d, f). As before, we averaged the speeds over the three sections of 


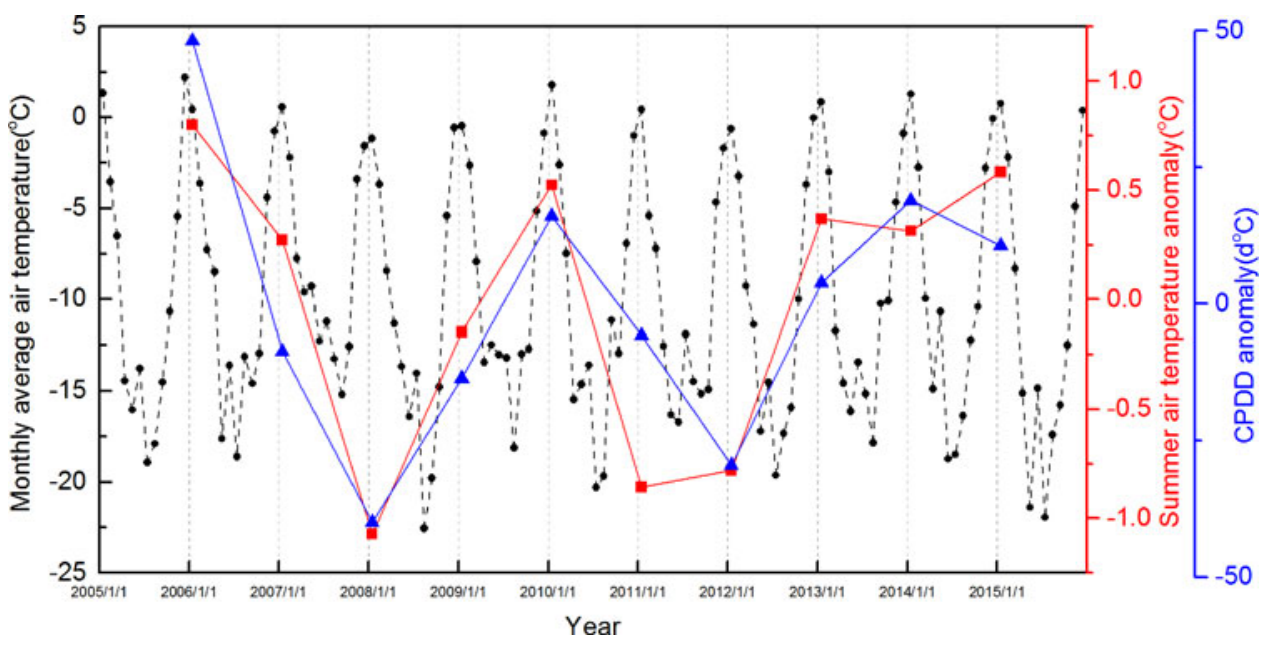

Fig. 4. Monthly average air temperatures (black), summer air temperature anomaly (red) and CPDD anomaly (blue) from 2005 to 2015 obtained from the AWS at Zhongshan Station.

the profile and removed the interannual trends. We find that both sections $A$ and $B$ of the glacier show similar seasonal patterns, with initial speedups typically start from September/October, reaching a maximum in December that is maintained into January, and a rapid decrease from February to April, reaching a minimum below the October speed. The upstream section (section B) speeds up by $\sim 50$ $\mathrm{m} \mathrm{a}^{-1}$ or $\sim 8 \%$, while the downstream section (section A) shows a larger amplitude speedup of $\sim 65 \mathrm{~m} \mathrm{a}^{-1}$, but a similarly large decrease from January to April of $\sim 100 \mathrm{~m} \mathrm{a}^{-1}$. Plotting the seasonal speed above the grounding zone (i. e. on grounded ice), we find no resolvable seasonal variability (Fig. 3f).

\subsection{Air temperatures and glacier surface melt}

The monthly average air temperatures (Fig. 4) from 2005 to 2015 show that January was usually the warmest month of the year. The only exception was 2005, which had a higher average air temperature in December. The years 2006, 2015 and 2010 had the top three highest average austral summer (December to next February) air temperatures $\left(-0.22{ }^{\circ} \mathrm{C}\right.$, $-0.44{ }^{\circ} \mathrm{C}$ and $-0.50{ }^{\circ} \mathrm{C}$, respectively). The CPDD anomaly fluctuated between 2006 and 2015, similar to the austral summer air temperature trend (Fig. 4).

Glacier surface melt typically increases with higher air temperatures (Lenaerts and others, 2017). We find that the meltwater lakes on PRG typically appear in early December and then expand rapidly in late December and January (Fig. 5b), peaking at the end of January and declining throughout February. Most meltwater lakes are distributed near the grounding line (Fig. 5a). Similar to previous observations at Langhovde Glacier in Dronning Maud Land (Langley and others, 2016), we detect a substantial number of lakes on the ice shelf that shrink while other lakes grow. Furthermore, some lakes (e.g. Lake 4 in Fig. 6) shrank from the outside in, suggesting potential englacial drainage.

\subsection{Ocean temperatures and sea ice concentration}

The ECCO2 time series of monthly ocean temperatures and temperature anomalies offshore of the PRG are shown in Figure $7 \mathrm{~b}$. In contrast to air temperatures, ocean temperatures peaked in April between 2005 and 2015. From 2005 to
2009, the temperatures steadily declined and a negative anomaly was detected during the years 2007-2009. In 2010, however, ocean temperatures experienced a large
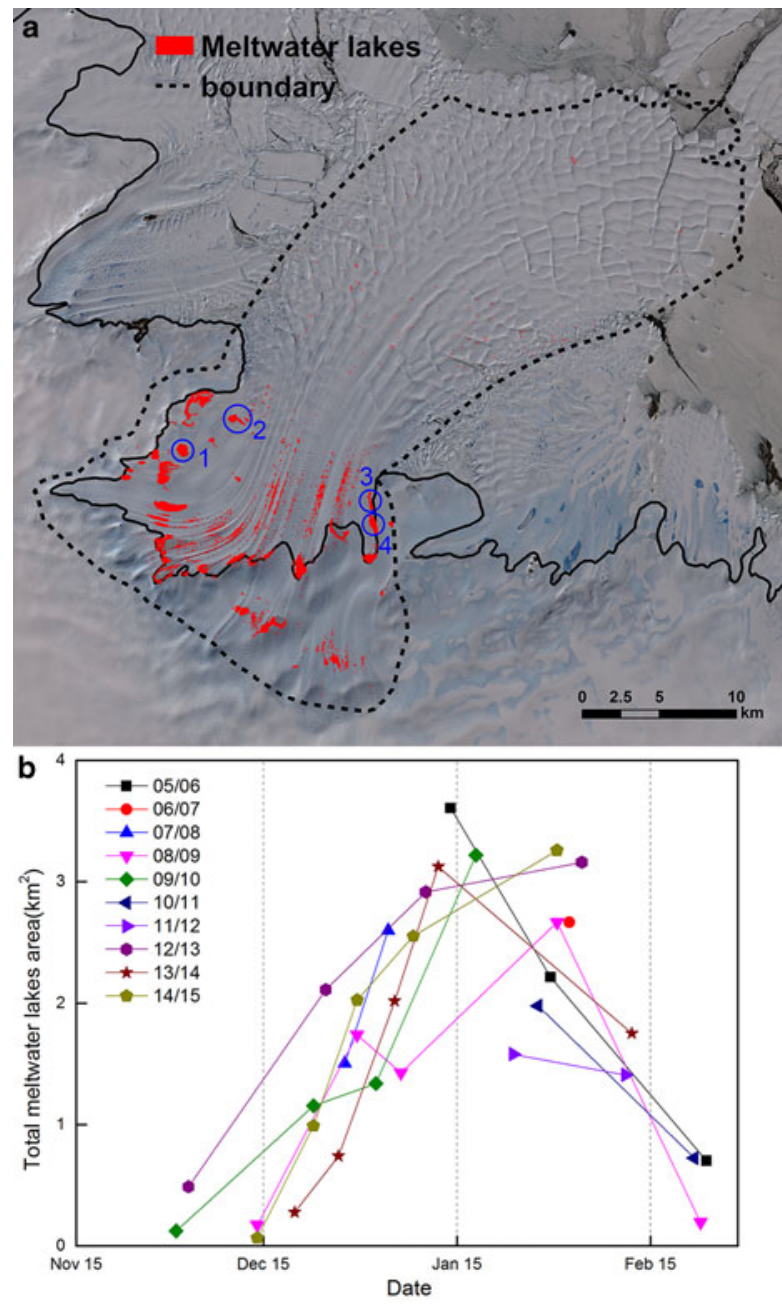

Fig. 5. (a) The distribution of the surface meltwater lakes observed from 2005 to 2015 . All the lakes inside the polygon boundary were manually digitized using either Landsat or ASTER images. The blue circle marked the location of lakes investigated in Figure 6. (b) The area evolution of the meltwater lakes in the PRG for the austral summer mapped from sequential Landsat and ASTER images. 

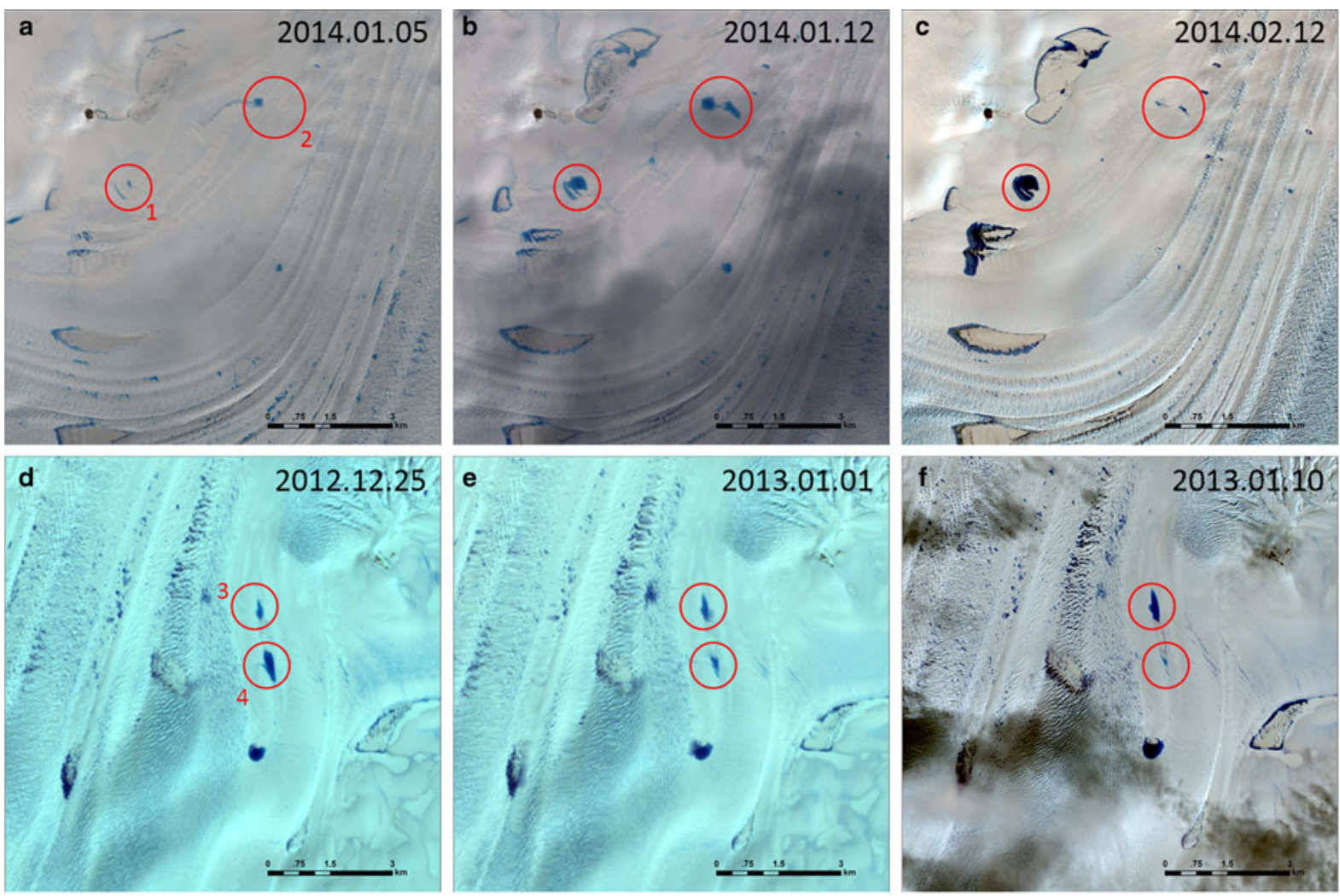

Fig. 6. (a-c) The evolution of Lake 2 from its formation to its disappearance, concurrent with Lake 1's continual growth. (d-f) Occasionally, neighboring lakes shrink (Lake 4) and grow (Lake 3) simultaneously.

increase of $\sim 0.3{ }^{\circ} \mathrm{C}$ (a positive anomaly of $\sim 0.2{ }^{\circ} \mathrm{C}$ ), reaching its highest recorded value. After 2010, the ocean temperature fell in 2011 and trended upward from 2011 to 2015. The positive temperature anomaly between 2013 and 2015 indicates the ocean temperature was higher than the 11-year average.

Daily sea ice concentrations from 1 June 2005 to 31 May 2015 at the glacier front are shown in Figure 8a. Sea ice concentration typically begins to decrease in late November, reaching a minimum in late February, and then rapidly increasing afterward. This late February sea ice minimum follows the January peak in air temperature and occurs just before the air temperatures drop below freezing. Besides, the analysis of monthly sea ice concentration anomaly indicates there was a significant negative sea ice anomaly from November to December 2014 (Fig. 8b). During this time, the sea ice concentration was $30 \%$ below the 10 years average, coinciding with the following 2015 calving event.

\section{DISCUSSION}

Our observations reveal substantial variation in the flow of PRG's ice shelf on both interannual and seasonal time scales between 2005 and 2015 (Fig. 3). The finding of a long-term increase in speed is contrary to the results of Liu and others (2017a) who found no significant speed changes from 2004 to 2015. This interannual speedup was highest at the ice front, decreasing to near zero at the grounding line, with no detectable change upstream. There were distinct increases in speed across the entire ice shelf in 2010 and at its seaward end in 2015.

Acceleration of an ice shelf can result from (1) increased flux into the shelf at the grounding zone, (2) thickening of the ice shelf due to decreased basal melting, which increases the hydrostatic stress and increases the ice shelf flow rate, (3) thinning and/or retreat from areas of resistance, such as islands, lateral shear margins and sea ice or (4) weakening of the ice shelf and its shear margins from surface meltwater. The first mechanism would require an increase in flow speed and thickening inland of the grounding zone, which we do not detect and is corroborated by the results of Gardner and others (2018). Paolo and others (2015) found no significant change in shelf thickness based on radar altimetry. Therefore, we assess the possibility of a change in flow resistance as an explanation for the observed speed increase.

Acceleration of the PRG ice shelf occurred during a period of sustained ice front advance, eliminating a loss of buttressing due to retreat as a possible cause of interannual acceleration. When the ice front calved and retreated in 2015 (Fig. S1), a small acceleration, localized to within $\sim 10 \mathrm{~km}$ of the ice front (Fig. 3a) was detected. Oceanic forcing is another possible cause of the interannual speed increase in the PRG. Intrusion of warm mCDW into Prydz Bay, as has been observed for the Amery Depression (HerraizBorreguero and others, 2015; 2016) and Totten Glacier (Rintoul and others, 2016), would increase the basal melt rate of ice tongue. Ice thinning would reduce the backstress generated by the ice shelf, initiating acceleration. The pattern of acceleration is consistent with ECCO2 ocean temperatures, showing a strong peak in temperatures in 2010, the same year we observe an abrupt increase in speed, followed by sustained interannual ocean warming. Furthermore, we calculate the mean ocean temperatures for April-August each year, which correspond to the general duration of the inflow of mCDW (Herraiz-Borreguero and others, 2015). A significant $\left(r^{2}=0.57, p<0.05\right)$ correlation 

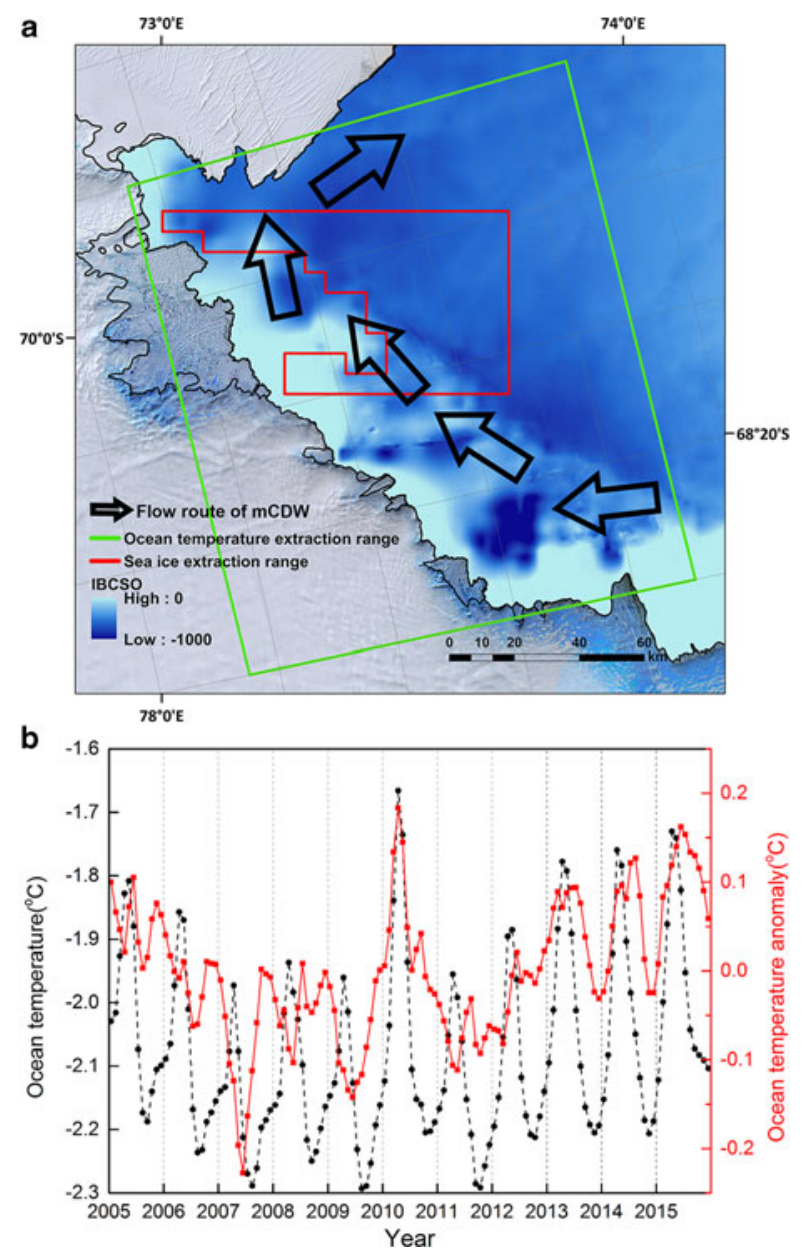

Fig. 7. (a) The ocean temperature and sea ice extraction range. The black arrows demonstrate the flow route of mCDW at the glacier front (Williams and others, 2016; Liu and others, 2017b). (b) The ECCO2 ocean potential temperatures and temperature anomaly (250-600 m depth) from 2005 to 2015.

exists between the annual speed and those mean ocean temperatures.

We find a distinct seasonality in ice flow speed with a maximum amplitude at the ice front, declining to near zero at the grounding line. The lack of seasonal acceleration over grounded ice eliminates variations in subglacial hydrology as a possible mechanism. Sea ice could also play an important role in ice shelf stability. On the one hand, the back-stress provided by sea ice can stabilize the ice front, shut down iceberg calving and prevent ice shelf crack propagation entirely (Walter and others, 2012; Moon and others, 2015; Robel, 2017). On the other hand, sea ice can alter the water column properties, e.g. sea ice formation in a polynya often accompanied by cold and saline water production. This could alter the winter water layer and link to basal melt rate variability (Khazendar and others, 2013; Dutrieux and others, 2014). In our case, the sea ice consolidates and grows thick in winter, which will provide an increasing amount of back-stress to the ice shelf and potential energy builds up in the ice shelf. Then sea ice begins to lose its rigidity and gradually break up in spring, leading to the release of stored energy. This will initiate the ice shelf acceleration in September/October. After that, the ice flow acceleration may mainly relate to the glacier surface meltwater. The timing of acceleration appears to be most consistent in timing with air temperatures. Both flow speed and air temperatures reach a maximum in early January, resulting in a maximum in the area of supraglacial melt lakes at the same time, which indicate peak meltwater production. We therefore hypothesize that the summer acceleration is due to weakening of the ice shelf by englacial penetration of meltwater and/or filling of crevasses, raising the ice temperature. This would soften the ice, causing locally faster flow without changing the large-scale stress regime of the ice shelf and impacting flow on grounded ice.

\section{CONCLUSIONS}

We measured both the long-term and seasonal ice velocities of the PRG from 2005 to 2015 . Ice flow accelerated by up to $10 \%$ since 2005 , with the acceleration increasing from zero at the grounding zone to a maximum at the ice front, and with the largest increase occurring in 2010, which we attribute to increased basal melting due to warm mCDW intrusions. We also detect a seasonal variation in velocity, increasing from approximately zero at the grounding zone to a maximum amplitude at the ice front. The timing of this seasonal variability agrees with sea ice break up in spring and the following onset of surface melting, which inferred from the extent of supraglacial lakes. This suggests that the
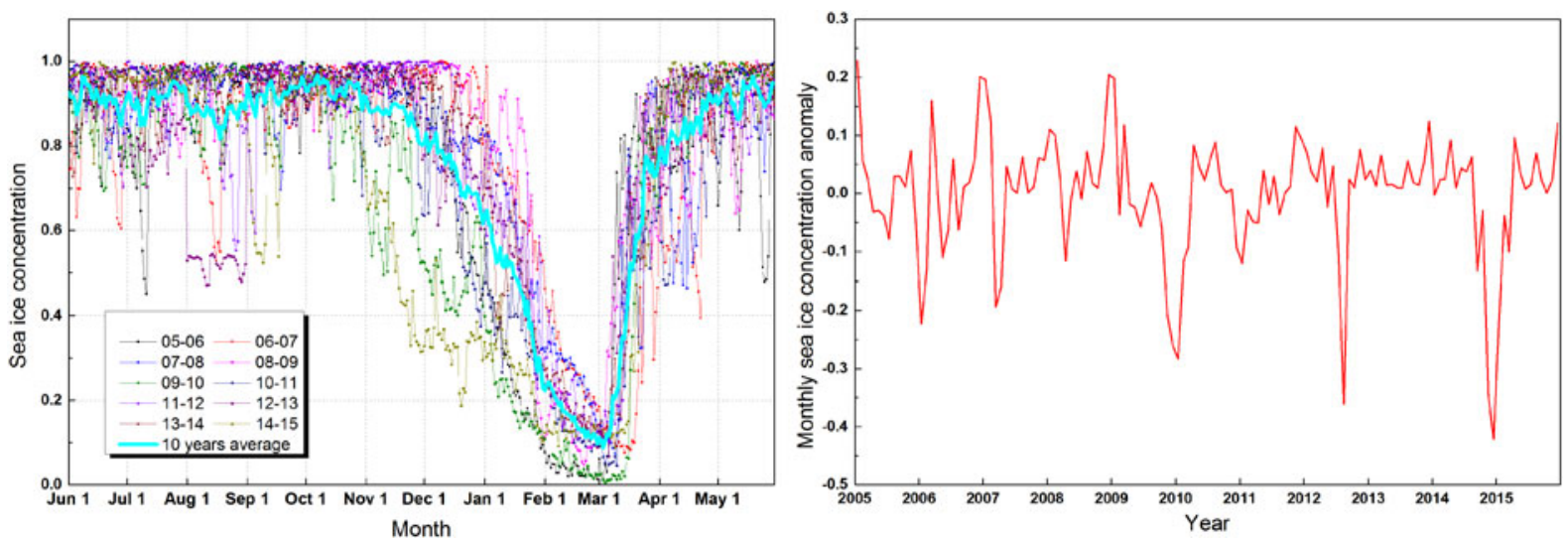

Fig. 8. (a) Daily sea ice concentration from 1 June 2005 to 31 May 2015 in Prydz Bay. Each line represents sea ice concentration from 1 June to the next 31 May. The thick cyan line indicates the 10-year mean sea ice concentration of each day. (b) The monthly sea ice concentration anomaly from January 2005 to December 2015. 
seasonal speedup may initially result from the lost back-stress provided by the sea ice in the austral spring and then due to weakening of the ice shelf by warming and infilling of crevasses. While our results add to the growing body of evidence suggesting substantial variability in the dynamics of East Antarctic outlet glaciers, they also underscore how little is known about the behavior of these glaciers on seasonal to interannual timescales, particularly in regard to forcing from ocean warming and surface melt. The increasing spatial and temporal resolution of observations available from spaceborne remote sensing, such as from ESA's Sentinel constellations and NASA's Landsat and upcoming ICESat-2 missions, will enable better understanding of multi-scale dynamics of these poorly known systems.

\section{SUPPLEMENTARY MATERIAL}

The supplementary material for this article can be found at https://doi.org/10.1017/jog.2019.6

\section{ACKNOWLEDGEMENTS}

This research was funded by the National Natural Science Foundation of China (NSFC) (41776200, 41531069 and 41376187), the Fundamental Research Funds for the Central Universities (2042015kf0189) and the China Scholarship Council (201506270085).

\section{REFERENCES}

Ahn Y and Howat IM (2011) Efficient automated glacier surface velocity measurement from repeat images using multi-image/multichip and null exclusion feature tracking. IEEE Trans. Geosci. Remote Sens., 49(8), 2838-2846

Bindschadler R and 17 others (2011) Getting around Antarctica: new high-resolution mappings of the grounded and freely-floating boundaries of the Antarctic ice sheet created for the International Polar Year. Cryosphere, 5, 569-588

Cassotto R, Fahnestock M, Amundson JM, Truffer M and Joughin I (2015) Seasonal and interannual variations in ice melange and its impact on terminus stability, Jakobshavn Isbræ, Greenland. J. Glaciol., 61(225), 76-88

Cruwys L and Rees G (2001) The Polar Record Glacier. Polar Rec., 37(201), 154-156

Dupont TK and Alley RB (2005) Assessment of the importance of iceshelf buttressing to ice-sheet flow. Geophys. Res. Lett., 32, L04503

Dutrieux P and 9 others (2014) Strong sensitivity of Pine Island IceShelf Melting to climatic variability. Science, 343(6167), 174178

Fraser AD, Massom RA, Michael KJ, Galton-Fenzi BK and Lieser JL (2011) East Antarctic Landfast Sea Ice distribution and variability, 2000-08. J. Clim., 25(4), 1137-1156

Fretwell P and 59 others (2013) Bedmap2: improved ice bed, surface and thickness datasets for Antarctica. Cryosphere, 7, 375-393

Gardner AS and 6 others (2018) Increased West Antarctic and unchanged East Antarctic ice discharge over the last 7 years. Cryosphere, 12(2), 521-547

Greene CA, Young DA, Gwyther DE, Galton-Fenzi BK and Blankenship DD (2018) Seasonal dynamics of Totten Ice Shelf controlled by sea ice buttressing. Cryosphere, 12(9), 2869-2882

Herraiz-Borreguero L and 5 others (2015) Circulation of modified Circumpolar Deep Water and basal melt beneath the Amery Ice Shelf, East Antarctica. J. Geophys. Res.-Oceans, 120, 30983112

Herraiz-Borreguero $L$ and 6 others (2016) Basal melt, seasonal water mass transformation, ocean current variability, and deep convection processes along the Amery Ice Shelf calving front, East Antarctica. J. Geophys. Res.-Oceans, 121, 4946-4965

Howat IM and Eddy A (2011) Multi-decadal retreat of Greenland's marine-terminating glaciers. J. Glaciol., 57(203), 389-396

Howat IM, Box JE, Ahn Y, Herrington A and McFadden EM (2010) Seasonal variability in the dynamics of marine-terminating outlet glaciers in Greenland. J. Glaciol., 56(198), 601-613

Jeong S, Howat IM and Ahn Y (2017) Improved multiple matching method for observing glacier motion with repeat image feature tracking. IEEE Trans. Geosci. Remote Sens., 55(4), 2431-2441

Khazendar A and 5 others (2013) Observed thinning of Totten Glacier is linked to coastal polynya variability. Nat. Commun., 4, 2857

Krug J, Durand G, Gagliardini O and Weiss J (2015) Modelling the impact of submarine frontal melting and ice mélange on glacier dynamics. Cryosphere, 9(3), 989-1003

Langley ES, Leeson AA, Stokes CR and Jamieson SSR (2016) Seasonal evolution of supraglacial lakes on an East Antarctic outlet glacier. Geophys. Res. Lett., 43, 8563-8571

Lea JM, Mair DWF and Rea BR (2014) Evaluation of existing and new methods of tracking glacier terminus change. J. Glaciol., 60(220), 323-332

Lenaerts JTM and 12 others (2017) Meltwater produced by windalbedo interaction stored in an East Antarctic ice shelf. Nat. Clim. Chang, 7, 58-62

Liu $Y$ and 7 others (2015) Ocean-driven thinning enhances iceberg calving and retreat of Antarctic ice shelves. Proc. Natl. Acad. Sci. USA, 112(11), 3263-3268

Liu T, Niu M and Yang Y (2017a) Ice velocity variations of the polar record glacier (East Antarctica) using a rotation-invariant featuretracking approach. Remote. Sens. (Basel), 10(1), 42

Liu C and 5 others (2017b) Modeling modified Circumpolar Deep Water intrusions onto the Prydz Bay continental shelf, East Antarctica. J. Geophys. Res.-Oceans, 122, 5198-5217

Menemenlis D and 7 others (2008) ECCO2: high resolution global ocean and sea ice data synthesis. Mercator Ocean Quarterly Newsletter, 31, 13-21

Miles BWJ, Stokes CR, Vieli A and Cox NJ (2013) Rapid, climatedriven changes in outlet glaciers on the Pacific coast of East Antarctica. Nature, 500, 563-566

Miles BWJ, Stokes CR and Jamieson SSR (2016) Pan-ice-sheet glacier terminus change in East Antarctica reveals sensitivity of Wilkes Land to sea-ice changes. Sci. Adv., 2(5)

Moon T and Joughin I (2008) Changes in ice front position on Greenland's outlet glaciers from 1992 to 2007. J. Geophys. Res., 113, F02022

Moon T, Joughin I and Smith B (2015) Seasonal to multiyear variability of glacier surface velocity, terminus position, and sea ice/ice mélange in northwest Greenland. J. Geophys. Res. Earth Surf., 120(5), 818-833

Mouginot J, Scheuchl B and Rignot E (2012) Mapping of ice motion in Antarctica using synthetic-aperture radar data. Remote. Sens. (Basel), 4, 2753-2767

Mouginot J, Rignot E, Scheuchl B and Millan R (2017) Comprehensive annual ice sheet velocity mapping using Landsat-8, Sentinel-1, and RADARSAT-2 data. Remote. Sens. (Basel), 9(4), 364

Paolo FS, Fricker HA and Padman L (2015) Volume loss from Antarctic ice shelves is accelerating. Science, 348(6232), 327-331

Paolo FS, Fricker HA and Padman L (2016) Constructing improved decadal records of Antarctic ice shelf height change from multiple satellite radar altimeters. Remote Sens. Environ., 177, 192-205

Pritchard HD and 5 others (2012) Antarctic ice-sheet loss driven by basal melting of ice shelves. Nature, 484(7395): 502-505

Rignot E, Mouginot J and Scheuchl B (2011) Ice flow of the Antarctic Ice sheet. Science, 333(6048), 1427-1430

Rignot E, Jacobs S, Mouginot J and Scheuchl B (2013) Ice-Shelf melting around Antarctica. Science, 341, 266-270 
Rignot E and 5 others (2019) Four decades of Antarctic Ice Sheet mass balance from 1979-2017. Proceedings of the National Academy of Sciences, 201812883

Rintoul SR and 6 others (2016) Ocean heat drives rapid basal melt of the Totten Ice Shelf. Sci. Adv., 2(12), e1601610

Robel AA (2017) Thinning sea ice weakens buttressing force of iceberg mélange and promotes calving. Nat. Commun., 8, 14596

Scambos TA, Bohlander JA, Shuman CA and Skvarca P (2004) Glacier acceleration and thinning after ice shelf collapse in the Larsen B embayment, Antarctica. Geophys. Res. Lett., 31(18), L18402

Schoof C (2007) Ice sheet grounding line dynamics: steady states, stability, and hysteresis. J. Geophys. Res. Earth Surf., 112, F03S28

Shepherd A and 46 others (2012) A reconciled estimate of ice-sheet mass balance. Science, 338, 1183-1189

Spreen G, Kaleschke L and Heygster G (2008) Sea ice remote sensing using AMSR-E 89-GHz channels. J. Geophys. Res.: Oceans, 113, $\mathrm{C} 02 \mathrm{~S} 03$
Strozzi T, Luckman A, Murray T, Wegmuller $U$ and Werner $\mathrm{CL}$ (2002) Glacier motion estimation using SAR offset-tracking procedures. IEEE Trans. Geosci. Remote Sens., 40(11), 2384-2391

The IMBIE team (2018) Mass balance of the Antarctic Ice Sheet from 1992 to 2017. Nature, 558(7709), 219-222

Walter JI and 6 others (2012) Oceanic mechanical forcing of a marine-terminating Greenland glacier. Ann. Glaciol., 53(60), 181-192

Weertman J (1974) Stability of the junction of an ice sheet and an ice shelf. J. Glaciol., 13(67), 3-11

Williams GD and 11 others (2016) The suppression of Antarctic bottom water formation by melting ice shelves in Prydz Bay. Nat. Commun., 7, 12577

Zhou C and 5 others (2014) Seasonal and interannual ice velocity changes of Polar Record Glacier, East Antarctica. Ann. Glaciol., 55(66), 45-51

MS received 8 March 2018 and accepted in revised form 22 January 2019; first published online 15 February 2019 